\title{
Internacionalização de empresas brasileiras: restrições de financiamento e papel do BNDES
}

Armando Dalla Costa*

Elson Rodrigo de Souza-Santos*

\begin{abstract}
RESUMO - Nos últimos anos passou a ser cada vez mais comum a existência de empresas internacionalizadas de países emergentes que apresentam grande competitividade, estratégias de inserção no mercado internacional e operações globais abrangendo setores tão diferentes quanto carnes, serviços de engenharia e informática. Entretanto, a expansão das empresas não ocorre apenas como um movimento estratégico rumo ao seu crescimento, mas sim apoiado por instituições públicas dos países de origem, especialmente fornecendo canais de financiamento. No Brasil, a principal instituição que alavanca os projetos de internacionalização de firmas nacionais no setor produtivo é o Banco Nacional de desenvolvimento Econômico e Social - BNDES. Essencial para viabilizar os planos de inserção no mercado internacional de empresas brasileiras e reduzir a barreira proveniente da falta de canais de financiamento de longo prazo oferecidos pela iniciativa privada.
\end{abstract}

Palavras-chave: Internacionalização de empresas. BNDES. Competitividade.

\section{INTRODUÇÃO}

Nas últimas décadas a integração da economia mundial se intensificou e o mercado e redes de fornecedores das empresas transpassaram as fronteiras nacionais. As aquisições, fusões e planos de expansão das firmas e inserção no mercado deixaram de ser restringidas pelas fronteiras nacionais. Por outro lado, percebeu-se uma transformação no sentido da evolução geográfica das multinacionais. O movimento que se iniciou nas décadas de 1950/1960, caracterizando-se como a primeira onda, envolveu sobretudo empresas de origem norte-americana e europeias. Na década de 1980 foi a vez das japonesas e coreanas. Por fim, a partir da virada do milênio chegou a hora das multinacionais dos países emergentes, com destaque para Brasil, China, Rússia e Índia.

A onda atual de internacionalização de empresas de países emergentes é caracterizada mais do que antes pelo apoio do Estado através de políticas de incentivo nos campos político, econômico e estratégico. Este esforço governamental permite que as firmas nacionais ganhem

\footnotetext{
* Doutor pela Université de Paris III (Sorbonne Nouvelle). É professor no Departamento de Economia e no Programa de Pós-Graduação em Desenvolvimento Econômico da Universidade Federal do Paraná. Coordenador do Núcleo de Pesquisa em Economia Empresarial (www.empresas.ufpr.br). Endereço eletrônico: ajdcosta@ufpr.br. ** Mestrando do Programa de Pós-Graduação em Desenvolvimento Econômico pela Universidade Federal do Paraná, membro do Núcleo de Pesquisa em Economia Empresarial - NUPEM. Bolsista do CNPq. Endereço eletrônico: elson129@gmail.com.
} 
musculatura e sejam competitivas no cenário internacional refletindo na estabilidade e poder econômico e político. Por exemplo, o Banco de Desenvolvimento da China (CDB, na sigla em inglês) é uma instituição estatal de apoio financeiro que criou um fundo inicialmente de 5,1 bilhões de dólares para a aquisição de companhias estrangeiras por empresas chinesas (EXAME, 2009). Em grande parte beneficiados pela crise econômica de 2007/2008 que reduziram o valor de mercado e fragilizaram empresas ao redor do mundo, especialmente no eixo Estados Unidos-Europa.

No Brasil, a emergência de multinacionais começou a ganhar corpo na década de 1970/1980, mas o grande salto ocorreu na década de 2000 quando companhias como JBSFriboi e Gerdau, respectivamente, nas áreas de carnes e siderúrgica passaram a ser grandes players globais de suas áreas de atuação. O movimento é visto pelo professor Fernado Santi (Instituto de Economia da Universidade Estadual de Campinas - Unicamp) como resultado do crescimento do mercado interno que permitiu às empresas ganharem musculatura para voos internacionais, além de ser uma forma de buscar novas alternativas de negócios e se manterem competitivas (VALOR, 2010, p. 10-11).

Entretanto, as empresas brasileiras enfrentam graves deficiências em obter recursos para financiar a internacionalização devido ao sistema financeiro brasileiro não estar suficientemente desenvolvido para fornecer recursos de longo prazo. Como mitigação das restrições de financiamento o BNDES assume o papel de financiador. Apesar de ser uma instituição pública que visa o fortalecimento da estrutura produtiva nacional e expansão das firmas brasileiras, não é uma entidade de caridade e visa a viabilidade dos investimentos e retorno dos recursos emprestados. Dessa forma o BNDES ganha uma importância vital para viabilizar projetos de internacionalização das empresas brasileiras ao tornar-se o principal incentivador.

Objetivando uma explicação e uma discussão a respeito do tema acima mencionado, este texto está organizado em três partes. A primeira aborda a deficiência do sistema financeiro brasileiro em apoiar o processo de internacionalização de empresas e o papel do BNDES na mitigação desses problemas. A segunda apresenta as motivações, estrutura e projetos concretos que tiveram o apoio do BNDES para serem viabilizados. A última apresenta as principais conclusões do trabalho.

\section{RESTRIÇÕES DE FINANCIAMENTO E PAPEL DO BNDES}

O fenômeno da integração econômica mundial reflete cada vez mais a construção das estratégias empresariais. Não apenas de multinacionais, mas também das empresas que são afetadas direta ou indiretamente pela concorrência externa, pelas redes de fornecedores estran- 
geiros que buscam novos mercados e oportunidades que transpassam as fronteiras nacionais, impulsionados pelos acordos pró-liberalização comercial fomentados no âmbito da Organização Mundial do Comércio (OMC) e a formação de blocos econômicos como União Europeia, Mercosul e APEC. Além do mais a integração econômica é facilitada pelo desenvolvimento dos meios de comunicação e transporte conjugados com a industrialização dos países em desenvolvimento e o seu novo papel como grandes mercados.

O cenário proveniente da crescente integração econômica permitiu a formação de ondas de empresas multinacionais na última metade de século XX em que Afonso Fleury (USP), departamento de engenharia de produção, observa três ondas de internacionalização de empresas (VALOR, 2010, p. 8). A primeira é protagonizada pelas norte-americanas seguidas das europeias nas décadas de 1950/1960. A segunda é formada por empresas japonesas seguidas das coreanas nas décadas de 1980/1990. A terceira e atual onda é caracterizada por firmas com origem nos países emergentes, sobretudo Índia, China, Brasil e Rússia. Não por acaso o comércio internacional é dominado por multinacionais em que no início da década de 1990 eram responsáveis por $75 \%$ do comércio mundial total, dos quais mais de um terço correspondia ao comércio intra firma (STOPFORD, 1994).

No Brasil, desde a década de 1980 passam a ser evidentes as empresas que apresentam força no mercado nacional, crescente capacidade competitiva e ambição de conquistar novos mercados. Num primeiro momento motivadas pela crise interna e necessidade de buscar novos ramos para a diversificação e ampliação dos mercados. Por exemplo, as construtoras que passaram a vender produtos de engenharia/construção para no exterior quando verificaram que o mercado nacional estava estagnado e escasso para novas grandes obras. Na década seguinte passaram a surgir grandes empresas dos mais diversos setores como mineração, alimentos, bebidas, finanças, papel e celulose que sobreviveram ao choque da abertura econômica e colocaram os mercados externos como fundamentais para seu crescimento e fortalecimento no mercado interno.

Quando o movimento de empresas multinacionais brasileiras começou a ganhar força, a quantidade de investimentos diretos no exterior provenientes do Brasil cresceu simultaneamente. Até o início da década de 1980 o estoque de investimentos de empresas brasileiras no exterior era irrelevante, situado em cerca de US\$900 milhões. No período entre 1983-1992 os investimentos diretos no exterior chegaram a totalizar US\$2,5 bilhões, ainda que concentrados no setor financeiro (37\%), Petrobras (30\%) e o setor manufatureiro situado em torno de $10 \%$. No censo de 2004 o volume total de investimentos brasileiros diretos no exterior alcançou US\$ 71 bilhões (ALEM; CAVALCANTI, 2005, p. 60-61). Essa cifra caiu em anos posterio- 
res em função da crise. Em 2010 pelas previsões do Banco Central os brasileiros aplicarão US\$ 15 bilhões lá fora ${ }^{1}$. Assim, é possível identificar que o setor externo possui uma crescente importância na economia brasileira e o país deixou de ser apenas um receptor de investimentos produtivos, mas também um investidor.

A importância crescente das multinacionais brasileiras motivou o Valor (2010) a lançar um número especial intitulado "multinacionais brasileiras: empresas e setores brasileiros globalizados" mostrando quem são as empresas, de quais setores, motivações, dificuldades e apoio que recebem. As empresas e setores que lideram o movimento de internacionalização vão de alimentos (Brasil Foods, Marfrig, Friboi), a siderurgia e mineração (Gerdau, Votorantim, Vale) a setores que exigem elevado grau de capacidade tecnológica como redes de tecnologia da informação e automação (Bematech). Dentro da heterogeneidade das empresas e setores é possível identificar as motivações gerais (ver Tabela 1), lideradas pela busca de competitividade e abastecer a demanda mundial, seguidas pelo aumento da escala, redução da dependência do mercado interno e estabelecer plataformas de exportação. Por último acompanhar o movimento de concorrentes e fugir da saturação do mercado interno.

TABELA 1 - MOTIVOS PARA BUSCAR O MERCADO EXTERNO EM (\%)

\begin{tabular}{lr}
\hline \multicolumn{1}{c|}{ Motivos } & $\mathbf{\%}$ \\
\hline Competitividade internacional & 25,90 \\
Demanda mundial & 19,50 \\
Busca de economias de escala & 15,10 \\
Redução da dependência do mercado interno & 13,70 \\
Estabelecer plataformas de exportação & 13,10 \\
Acompanhar concorrentes no exterior & 9,80 \\
Saturação do mercado interno & 2,00 \\
outros & 1,00 \\
\hline
\end{tabular}

FONTE: Sobeet.

Extraído do Valor (2010, p.10).

Entretanto, as empresas brasileiras que se internacionalizam sofrem com o problema de como financiar o investimento no exterior, não muito diferente da questão de como financiar o investimento de longo prazo visando o mercado interno. Nos dois casos as firmas esbarram na dificuldade de obter crédito no mercado privado brasileiro derivado da própria história do sistema de financiamento do país mostrada em trabalhos como de Studart (1995) e Carvalho et al. (2002). Assim como observam Curado, Dalla Costa e Souza-Santos (2010) a dificuldade de financiamento representa um entrave para as empresas crescerem e conquistarem mercados 1 Multinacionais brasileiras já investiram mais de US\$ 8 bilhões no exterior desde o início do ano até maio de 2010. Dados disponíveis em <http://www.estadao.com.br/estadaodehoje/20100529/not_imp558378,0>. Acesso em: 14 nov. 2010. 
além das fronteiras nacionais. Resta às firmas alavancar os investimentos utilizando recursos próprios ou recorrer a instituições públicas que fazem o papel no fornecimento de crédito de longo prazo, especialmente o BNDES. Porém como consta no caderno do Valor (2010) a maioria das empresas utiliza recursos próprios.

\section{PAPEL DO BNDES E INCENTIVO A INTERNACIONALIZAÇÃO}

O movimento de internacionalização de empresas normalmente tende a ser apoiado de alguma forma pelos governos nacionais. Por exemplo, a Overseas Private Investment Corporation (OPIC) é uma agência dos EUA que organiza missões de investimento para o setor privado norte-americano, financia projetos, fornece garantias e seguros contra riscos não comerciais. Outro exemplo é no Japão em que existem cerca de oito agências que patrocinam os investimentos diretos no exterior, com destaque para o Japan Bank for International Cooperation (JBIC), sucessor do Eximbank of Japan. Inicialmente criado na década de 1950 para financiar as exportações e importações, ao longo do tempo passou a financiar investimento no exterior (ALEM; CAVALCANTI, 2005, p. 66-67).

Entretanto, o apoio a internacionalização de empresas suscita a discussão dos favoráveis e contrários. Os contrários argumentam que existe a possibilidade de "exportação" de empregos, perda de divisas e redução dos níveis de investimento doméstico. Os favoráveis ressaltam que o fortalecimento das empresas nacionais eleva a competitividade e aumenta a criação de empregos, as empresas globalizadas possuem maior capacidade de sobrevivência frente a concorrentes internacionais e podem ser protagonistas nas atividades de pesquisa $\&$ desenvolvimento - P\&D (ALEM; CAVALCANTI, 2005, p. 55-56). De outro lado, permite atender clientes que não podem ser atendidos pelo comércio tais como serviços, indiretamente incentivando a exportação de equipamentos e insumos do país de origem. Adicionalmente, a vulnerabilidade externa inicial originária do envio de recursos pode ser atenuada pela solidificação do país como um credor internacional, permitindo maior segurança e fluxo de recursos no longo prazo.

Assim, o BNDES constitui um suporte importante para a internacionalização de empresas, apesar do Brasil ainda não ter uma política explícita e estruturada para promover a criação de multinacionais brasileiras. Entretanto, a ação do BNDES uma manifestação das novas diretrizes da política externa inauguradas no governo Luiz Inácio Lula da Silva começa a dar os primeiros passos nesta direção, visto por Souza (2010) como ações no sentido da cooperação/ integração objetivando tanto a "busca da paz" centrada no poder econômico-financeiro. Tanto que quando se observa as conclusões do artigo de Alem e Cavalcanti (2005) sobre os motivos que o BNDES e o Estado brasileiro precisam apoiar a internacionalização citam o fortaleci- 
mento das empresas nacionais, competitividade, aumento das exportações, geração de divisas e acesso a tecnologia.

No âmbito do BNDES a posição favorável ao apoio a internacionalização se sobrepôs aos contrários. Em uma entrevista dada por Luciano Coutinho, presidente do BNDES, a revista América Economia (2010), enfatiza o simbolismo da abertura da representação oficial do banco no Uruguai, considerando um marco rumo a internacionalização das empresas brasileiras, em especial na América Latina. Nos primeiros oito meses de 2009 o BNDES desembolsou cerca de US \$ 600 milhões para financiar as operações das empresas brasileiras na América Latina. O objetivo não é apenas dar suporte ao aumento das exportações brasileiras para os países da região, mas alavancar a expansão das empresas brasileiras através das filiais e venda de produtos não comercializáveis como serviços de engenharia. Por exemplo, a expansão do metrô de Caracas, Venezuela, é construída pela filial da empresa brasileira Odebrecht, financiada pelo BNDES e que importa do Brasil cerca de $60 \%$ dos equipamentos e insumos utilizados na obra.

Dessa forma, o BNDES apoia a internacionalização de empresas através dos elementos: i) liberalização das restrições aos investimentos diretos no exterior - tendo em vista que implicam saída de divisas (isso foi particularmente relevante no caso de países em desenvolvimento e nas economias em transição); ii) criação de instrumentos internacionais que facilitem e protejam os investimentos no exterior; iii) informação e assistência técnica; iv) incentivos fiscais; v) mecanismos de seguros para os investimentos; e v) financiamento (ALEM; CAVALCANTI, 2005). Por outro lado, no site oficial do BNDES (2010), existe a área denominada "exportação e inserção internacional" onde são apresentados os produtos e programas oferecidos pelo banco.

Produtos:

- BNDES Finem: financiamento de valores superiores a $\mathrm{R} \$ 10$ milhões a projetos de implantação, expansão e modernização de empreendimentos realizados de duas formas: i) apoio a internacionalização de empresas brasileiras fornecendo capital de giro; e ii) aquisição de bens de capital nacional no mercado internacional.

- BNDES Automático: financiamento de até $\mathrm{R} \$ 10$ milhões a projetos de implantação, expansão e modernização de empreendimentos.

- BNDES Exim: financiamento à produção de bens e de serviços brasileiros destinados à exportação e à comercialização destes itens no exterior. 
Programas:

- BNDES Pró-Aeronáutica - Exportação: financiamento à produção de bens e serviços destinados à exportação por parte de MPMEs integrantes da cadeia produtiva da indústria aeronáutica brasileira, nas fases pré-embarque e pós-embarque.

- BNDES Profarma - Exportação: financiamento à exportação de bens e serviços nacionais, inseridos no complexo industrial da saúde, nas fases pré-embarque e pósembarque.

- BNDES Proplástico - Fortalecimento das Empresas: apoio à internacionalização de empresas de capital nacional da cadeia produtiva do plástico.

- BNDES Prosoft - Exportação: financiamento à exportação de software e serviços de TI nacionais, nas fases pré-embarque e pós-embarque.

- BNDES PSI - Exportação Pré-embarque: financiamento, na fase pré-embarque, à produção de bens de capital destinados à exportação.

\section{CONSIDERAÇÕES FINAIS}

O Brasil, se comparado com a Índia e China está atrasado do ponto de vista da quantidade e condições de multinacionais próprias. Sobretudo a China, em função do tamanho de sua economia, do seu mercado interno e do forte crescimento das últimas décadas está em vantagem tanto no número de firmas multinacionais quanto em termos de instrumentos de apoio à internacionalização.

No Brasil o sistema financeiro não assumiu o compromisso de financiar o crescimento externo das empresas e estas, junto com as organizações que as representam, não conseguiram implementar mecanismos junto aos bancos privados que pudessem dar sustento ao processo de criação de grupos com capacidade e tamanho suficiente para atuar no exterior.

Para suprir parte desta demanda, o BNDES constitui uma importante instituição de fomento, preenchendo uma lacuna deixada pela iniciativa privada em relação ao fornecimento de linhas de crédito para investimentos de longo prazo. Ao mesmo tempo, assume a função de principal fomentadora da internacionalização de empresas e incorporando uma nova faceta da política externa brasileira encampada no governo Lula.

Um dos objetivos dos novos diretores da instituição é o de permitir e apoiar a formação de grandes grupos que tenham condições de atuar no mercado internacional. Por outro 
lado, a pretensão é que tais conglomerados tornem-se referências internacionais e possam influir nos preços e nas estratégias adotadas pelos respectivos setores que representam.

\section{REFERÊNCIAS}

ALEM, A. C.; CAVALCANTI, C. E. O BNDES e o apoio à internacionalização das empresas brasileiras: algumas reflexões. Revista do BNDES, Vol. 12, n. 24, Dezembro, p. 42 - 76, 2005 .

AMÉRICA ECONOMIA. Expansión Sin Freno. Publicado em: 01 set. 2010. Disponível em: $<$ http://www.americaeconomia.com/negocios-industrias/expansion-sin-freno $>$. Acesso em: $31 / 11 / 2010$.

BNDES. Onde Estou? > Página Inicial> Áreas de Atuação > Empostação e Inserção Internacional. Disponível em: < http://www.bndes.gov.br/SiteBNDES/bndes/bndes_pt/Areas_de_ Atuacao/Exportacao_e_Insercao_Internacional/>. Acesso em: 21/10/2010.

CARVALHO, C. E.; STUDART, R.; ALVES Jr.; A. J. Desnacionalização do setor bancário e financiamento das empresas: a experiência brasileira recente. IPEA, Textos Para Discussão $\mathrm{n}^{\mathbf{0}} 882,2002$.

CURADO, M. L.; DALLA COSTA, A. J.; SOUZA-SANTOS, E. R. Sistema financeiro e setor produtivo brasileiro: evidências e consequências sobre as empresas nacionais. In: XV Encontro Nacional de Economia Política, 2010, São Luis. Anais do XV Encontro Nacional de Economia Política. São Luis : Editado pela Sociedade Brasileira de Economia Política. v. 1. p. 1-20, 2010.

MULTINACIONAIS brasileiras já investiram mais de US\$ 8 bilhões no exterior desde o início do ano até maio de 2010. Dados disponíveis em: <http://www.estadao.com.br/estadaodehoje/20100529/not_imp558378,0>. Acesso em: 14/11/2010.

SOUZA, A. M. O Expansionismo nos Governos Lula e o BNDES. Boletim Meridiano 47, Vol. 11, n. 120. Disponível em: < http://seer.bce.unb.br/index.php/MED/article/download/581/756>. Acesso em: 09/09/2010.

STOPFORD, J. M. The growing interdependence between transnational corporations and governments. Transnational Corporations, Vol. 3, n. 1, 1994.

STUDART, R. Investment finance in economic development. Londres e Nova York: Routledge, 1995.

VALOR. Multinacionais brasileiras: empresas e setores brasileiros globalizados. 09/2010. 